\title{
Comparison of the efficiency of sodium nitrate and superphosphate as nutrients in the bioremediation of petroleum hydrocarbon polluted water
}

\section{Efeovbokhan, Vincent Enon. ${ }^{1}$, Anawe, Paul Apeye Lucky ${ }^{2}$, Makinde, Favour Adejare ${ }^{3}$ and Odunmbaku, Omolu ${ }^{4}$}

\author{
${ }^{1,4}$ Chemical Engineering Department, Covenant University, Ota, Nigeria. \\ ${ }^{2,3}$ Petroleum Engineering Department, Covenant University, Ota, Nigeria.
}

\begin{abstract}
The effect of Aspergillus Niger stimulated with $0.2 \mathrm{M}$ sodium nitrate and $0.2 \mathrm{M}$ single superphosphate fertilizer (nutrients) was investigated in this study. The ambient temperature averaged $29^{\circ} \mathrm{C}$ all through the 25 days of the research. The comparison was done using three setups- two samples of the hydrocarbon polluted water were amended with the nutrients and with Aspergillus Niger. The third sample served as control. After twenty five days, it was observed that the sample amended with $0.2 \mathrm{M}$ sodium nitrate went through the highest amount of bioremediation: For the total hydrocarbon content, the sample with $0.2 \mathrm{M}$ sodium nitrate in it dropped by $78.62 \%(393-84 \mathrm{mg} / \mathrm{L})$, the sample with $0.2 \mathrm{M}$ superphosphate in it $-72.5 \%(393-$ $108 \mathrm{mg} / \mathrm{L})$ and the control sample with the lowest drop of $52.16 \%(393-188 \mathrm{mg} / \mathrm{L})$. For the biological oxygen demand, the sample with $0.2 \mathrm{M}$ sodium nitrate in it dropped by $71.60 \%(1832.6$ - 520.47), the sample with $0.2 \mathrm{M}$ superphosphate in it dropped by $63.37 \%(1832.6-671.3 \mathrm{mg} / \mathrm{L})$ and the control sample had the lowest drop of $50.27 \%(1832.6-911.29 \mathrm{mg} / \mathrm{L})$. The $\mathrm{pH}$ of the samples with nutrients in them were initially acidic but became less acidic with time while the control sample which was initially neutral became more acidic.
\end{abstract}

Keywords: Bioremediation, Efficiency of Nutrients, Aspergillus Niger and Polluted Water

\section{INTRODUCTION}

The development of petroleum industry into new frontiers, the apparent inevitable spillages that occur during routine operations and records of acute accidents during transportation has called for more studies into oil pollution problems (Timmis et al., 1998), which has been recognized as the most significant contamination problem (Snape et al., 2001). Oil is a complex mixture of hydrocarbons and other organic compounds, including some organometallic constituents (Butler and Mason, 1997). It contains hundreds or thousands of aliphatic, branched and aromatic hydrocarbons (Prince, 1993; Wang et al., 1998), most of which are toxic to living organisms (ATSDR, 1995). In large concentrations, the hydrocarbon molecules that make up crude oil and petroleum products are highly toxic to many organisms, including humans. Diesel one of the components of crude oil for instance, does not biodegrade easily, so toxins can persist for years in the environment and lead to an accumulated concentration over time with environmental impacts including:(i) Decreased plant and animal growth, (ii) Disrupted reproductive cycles, (iii) Localized death of plants and animals, (iv) Disruption of migratory routes used by water birds and marine life (Paula, 2007).
Fat soluble components may accumulate in the organs of animals and may be enriched in the food chain, even up to humans (Mackay et al., 2000). Prolonged exposure and high oil concentration may cause the development of liver or kidney disease, possible damage to the bone marrow and an increased risk of cancer (Propset et al., 1999; Lloyd and Cackette, 2001; Mishra et al., 2001).

And because petroleum is also the raw material for many other chemical products such as plastics, paints, cosmetics etc, the potential for oil spills is significant. The volume of spills usually exceeds the inherent remediation capacity for any given environment, resulting in a significant ecological impact (Yehunda, 2002). Accidental and deliberate crude oil spills has been and still continue to be a significant source of environmental pollution and poses a serious environmental problem due to the possibility of air, water and soil contamination. (Trindade et al., 2005).

Bioremediation has been advanced as one of the promising technologies that can be used to quickly and effectively remedy the adverse effects of petroleum hydrocarbon pollution in potential oil spill areas. It is simply the act of adding materials such as 
nutrients, microbial products or microorganisms and aeration to contaminated areas (Chuma, 2010).

Claude E. ZoBell had as far back as 1946, recognized that many microorganisms have the ability to utilize hydrocarbons as the sole source of carbon and energy. He further recognized that the microbial utilization of hydrocarbons were highly dependent on the chemical nature of the components in the petroleum mixture and environmental determinants (Atlas, 1981). Microbial biodegradation of pollutants has intensified in recent years as mankind strives to find sustainable ways to clean up contaminated environments (Diaz, 2008). Biodegradation of hydrocarbons by natural populations of microorganisms represent one of the primary mechanism by which petroleum and other hydrocarbon pollutants are eliminated from the environment.

It is well known that there are several microbial species found in soil and water that are capable of assimilating these petroleum hydrocarbons. Unfortunately, the rate of microbial assimilation of petroleum hydrocarbons is relatively slow. It is necessary, therefore, to enhance the biological process if bioremediation is to be utilized in removing such pollutants from soils and water. This technology accelerates the naturally occurring biodegradation under optimized conditions such as oxygen supply, temperature, $\mathrm{pH}$, the presence or addition of suitable microbial population (bio-augmentation) and nutrients (bio-stimulation), water content and mixing (Trindade et al., 2005). In petroleum spills, there is no lack of electron donors (petroleum hydrocarbons), so microbial metabolism is generally limited by the availability of electron acceptors (such as oxygen, nitrate, sulphate, or $\mathrm{Fe}$ (III), or by the availability of essential nutrients (such as nitrogen, potassium and phosphate). The basic principle of engineered bioremediation systems is to relieve the lack of electron acceptors and nutrients and thereby increase the rates of petroleum hydrocarbon degradation, (Francis, 1999). Thus, microbial nutrients, especially nitrogen containing nutrients like urea and ammonium nitrate have been added to contaminated soil or water as a method for enhancing the biodegradation of the hydrocarbon contaminants (Irvin and Lin, 1998). The ability to actively decompose specified fractions of petroleum hydrocarbon is expressed by many micro organisms (Bartha and Atlas, 1997). Some of these microbes include Pseudomonas, E.coli, clostridium, Candida, Aspergillus niger, Yeasts, Penicillium and a host of others (Zobell, 1994, Okoh, 2001: Barth, 2003; Lliros et al., 2003; Chailana et al., 2004 Adekunle et. al, 2007; Obahiagbon and Owabor, 2008).

\section{MATERIALS AND METHODS}

Sample collection: The crude oil, Forcados, used for this study was obtained from an Oil Producing Company located in the Niger Delta region of Nigeria.

Sample Preparation: The Crude oil polluted water was made by adding $300 \mathrm{ml}$ of Forcados light to 3000 $\mathrm{ml}$ of water in three different kegs. The sodium nitrate is added to one sample while superphosphate is added to a second sample while the third one is left without any of the nutrients and would be treated as a control sample. This crude oil polluted water of ratio $1: 10$ was then stored in black plastic containers at an ambient temperature of $29^{\circ} \mathrm{C}$ until the start of the experiment.

The 0.2M Sodium Nitrate Sample was made by adding $46.86 \mathrm{~g}$ of sodium nitrate to $3,300 \mathrm{~mL}$ of the crude oil- distilled water mixture. The $0.2 \mathrm{M}$ Superphosphate was made by adding $154.47 \mathrm{~g}$ of Superphosphate to $3,300 \mathrm{~mL}$ of the crude oil- distilled water sample.

The Aspergillus Niger is then inoculated into the two samples.

\section{TOTAL HYDROCARBON CONTENT (THC)}

Procedure: The oil content of the water was determined by shaking $5 \mathrm{~g}$ of a representative water sample with $10 \mathrm{ml}$ of toluene and the oil extracted was determined by the absorbance of the extract at $450 \mathrm{~nm}$ in a spectrophotometer.

A standard curve of the absorbance of different known concentrations of oil in the organic phase was first drawn; after taking readings from the spectrophotometer, oil concentrations, in the water sample were then calculated after reading the concentration of the oil in the extract from the standard curve. With reference to the standard curve, the oil concentration was calculated. Measurement

Apparatus: An electronic $\mathrm{pH}$ meter with temperature compensation adjustment, Jenway 6405 UV/VIS Spectrophotometer, thermometer, glass rod buffer solutions and samples

Procedure: The $\mathrm{pH}$ meter was first calibrated using appropriate buffer solutions. The sample was thoroughly mixed together using a glass rod and its $\mathrm{pH}$ taken. The $\mathrm{pH}$ value obtained was then recorded. 


\section{Biochemical Oxygen Demand (BOD)}

Reagents used:

1. Winkler's solution A

2. Winkler's solution $B$

3. Starch solution

Procedure: Two $250 \mathrm{ml}$ reagent bottles were filled up completely with the sample and stoppered tightly. To one of the bottles, $1.5 \mathrm{ml}$ each of Winkler's Solution A and B were added, and precipitant was formed.

The precipitant was dissolved with $2 \mathrm{ml}$ of concentrated sulphuric acid to form a golden brown solution. $50 \mathrm{ml}$ of the resulting solution was poured into $250 \mathrm{ml}$ conical flask and 3 drops of starch indicator were added and titrated against $0.2 \mathrm{M}$ Sodium thiosulphate $\left(\mathrm{Na}_{2} \mathrm{~S}_{2} \mathrm{O}_{3}\right)$ with initial blue black coloration and the volume of $0.2 \mathrm{M}\left(\mathrm{Na}_{2} \mathrm{~S}_{2} \mathrm{O}_{3}\right)$ solution used was recorded and after titrating, it turned colourless. The second bottle was covered with black cellophane bag or aluminum foil to prevent the penetration of light and then incubated at $29^{\circ} \mathrm{C}$ for 5 days. At the end of 5 days, the step above was repeated and the volume of $0.1 \mathrm{~N} \mathrm{Na}_{2} \mathrm{~S}_{2} \mathrm{O}_{3}$ used was recorded

The BOD of the sample was calculated as follows:

$B O D_{5}=\left(D O_{0}-D O_{5}\right)$

Where;

$\mathrm{DO}_{0}=$ Dissolved oxygen concentration at zero time

$\mathrm{DO}_{5}=$ Dissolved oxygen concentration after 5 days incubation period

Different set of readings were taken and recorded at interval of 5 days for 25 days.

\section{DISCUSSION OF RESULTS}

The influence of Aspergillus Niger, 0.2M Sodium Nitrate $\quad\left(\mathrm{NaNO}_{3}\right), \quad 0.2 \mathrm{M}$ superphosphate $(3 \mathrm{Ca}(\mathrm{H} 2 \mathrm{PO} 4) 2 . \mathrm{H} 2 \mathrm{O})$ on the bioremediation of hydrocarbon polluted water was investigated at ambient temperature of $29^{\circ} \mathrm{C}$. Physicochemical parameters such as Biological Oxygen Demand (BOD), Total Hydrocarbon Content (THC) and $\mathrm{pH}$ were monitored as indicators of the degree of bioremediation.
Variation of the total hydrocarbon content of the three samples with time : From Fig.1, it was observed that the sample to which $0.2 \mathrm{M}$ sodium nitrate was added has the highest drop of $78.62 \%$ (from $393-84 \mathrm{mg} / \mathrm{L}$ ) in its total hydrocarbon content followed by the sample with $0.2 \mathrm{M}$ superphosphate in it with a drop of $72.5 \%$ (from $393-108 \mathrm{mg} / \mathrm{L}$ ) and finally the lowest drop with the control sample of $52.16 \%$ (from $393-188 \mathrm{mg} / \mathrm{L}$ ). The samples with $0.2 \mathrm{M}$ sodium nitrate and $0.2 \mathrm{M}$ superphosphate cause higher drops in the total hydrocarbon content than that of the control sample. This is because Aspergillus Niger thrives well in the presence of nutrients such as nitrates, phosphates and a host of others. This results in a more rapid growth of the fungus and finally, a more rapid decomposition of the crude oil. But it seems that nitrates are more important than phosphates in bioremediation strategies, because the sample with $0.2 \mathrm{M}$ sodium nitrate has a higher THC drop than that of the $0.2 \mathrm{M}$ Superphosphate Sample. Nitrates are essential because they provide nitrogen which is the building block of amino acids and also the building block of proteins, the most important component of any living organism.

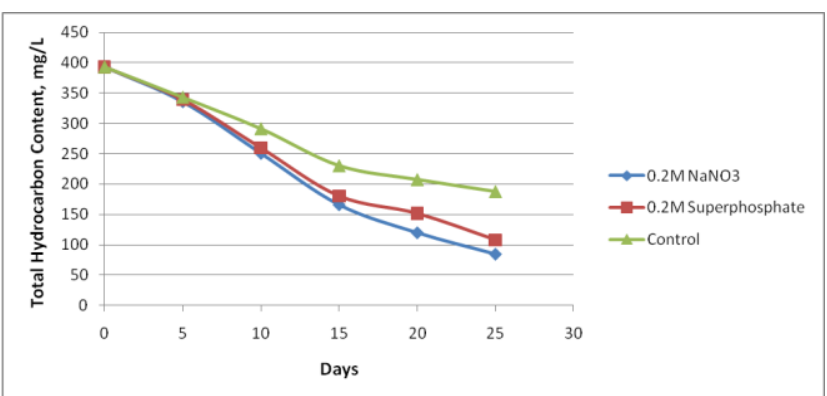

Fig.1 Total Hydrocarbon content vs. Time Graph of the three samples

Variation of the biological oxygen demand of the three samples with time: From Fig. 1 a progressive decline in the BOD of the three samples was observed. The sample that has the highest drop in the biological oxygen demand is the sample with $0.2 \mathrm{M}$ sodium nitrate in it with a drop of $71.60 \%$ (from $1832.6-911.29 \mathrm{mg} / \mathrm{L}$ ) followed by the sample with $0.2 \mathrm{M}$ superphosphate in it with a drop of $63.37 \%$ (from $1832.6-671.3 \mathrm{mg} / \mathrm{L}$ ) and finally the control sample recorded the lowest drop of $50.27 \%$ (from $1832.6-520.47 \mathrm{mg} / \mathrm{L})$. 


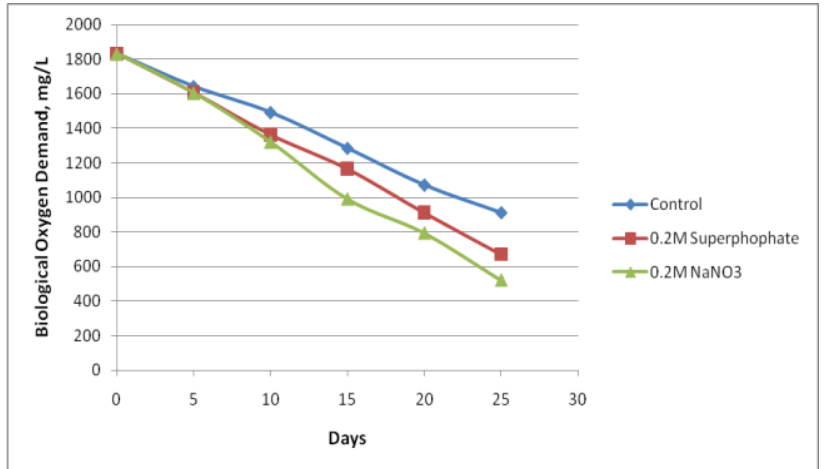

Fig.1 Biological Chemical Demand vs. Time Graph of the three samples

The drop in BOD for samples can be attributed to activities of the Aspergillus niger and other indigenous microbes present in them which convert the hydrocarbons into less toxic substances such as $\mathrm{CO}_{2}, \mathrm{H}_{2} \mathrm{O}$ and many intermediates like organic acids, lipids, esters, complex alcohols and microbial proteins in form of enzymes (Phillip et al, 1989). The sodium nitrate and the single super phosphate added to samples 1 and 2 respectively led to rapid growth of the fungi in the two samples and hence greater demand for oxygen as the fungi biodegrade the hydrocarbon. The control sample showed the least drop in BOD authenticating the positive effect of nutrients in bioremediation.

\section{Variation of the $\mathrm{pH}$ of the three samples with time:}

From Fig.1, it can be seen that the $\mathrm{pH}$ of the control sample dropped from the neutral $\mathrm{pH}$ down to a more acidic value of around 6.84. This suggests that the indigenous microbes are converting the hydrocarbon into more of alkanoic acid than carbon dioxide and water and hence the lowering of the $\mathrm{pH}$ of the sample is observed.

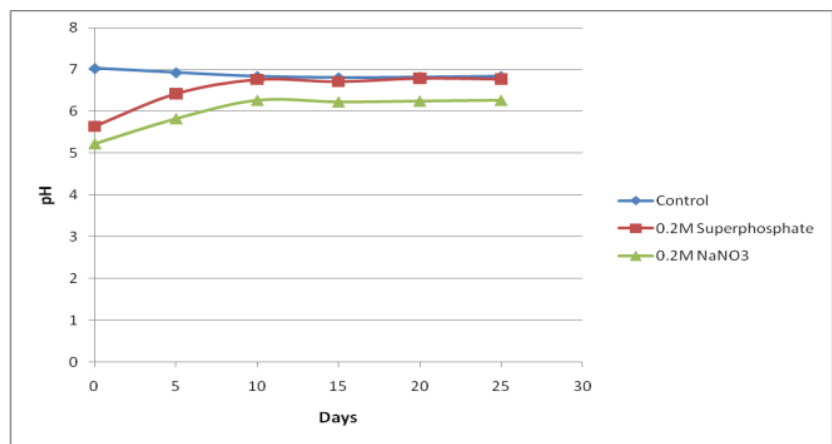

Fig.1 pH vs. Time Graph of the three samples
Also, it is observed that the initial $\mathrm{pH}$ of the other two samples are acidic, this is because of the acidic nature of sodium nitrate and superphosphate but as time goes on, the samples became less acidic as the fungi use up these nutrients to biodegrade the hydrocarbon, yielding carbon dioxide and water hence also making the sample less acidic. The $\mathrm{pH}$ values of the control sample and that to which sodium nitrate was added peaked at 6.84 while $\mathrm{pH}$ of the sample to which single superphosphate was added gave 6.3, suggesting that the optimum $\mathrm{pH}$ for bio-remediation of hydrocarbon polluted water under these conditions lies between 6 and 7 .

As it is, the $0.2 \mathrm{M}$ Sodium Nitrate sample is bioremediating faster than the others. The reasons for this could be as follows. Although, phosphates are necessary for the cell division of fungi, if there is a disruption of the main enzymes that are formed by the use of phosphates, Trehalose-6- Phospate synthetase tps $A$ and tps $B$, there will only be a very little change in the intake of the hydrocarbon. This means that even in the absence of phosphates the fungi would still be able to use the hydrocarbon (Marcus et al, 2007). Also, nitrates are the building block of proteins formed in the fungi and are necessary for cell growth and improved yield and so a lack of this nutrient will cause a decrease in the yield of the fungi. The control sample lacks all these basic macronutrients with the exception of a carbon source and hence it did not perform as much as the other two samples.

\section{CONCLUSION}

Bioremediation as a technology for cleanup of oil spills has been shown to have the capability to return the natural environment altered by hydrocarbon contaminants to its original condition. This was observed in the drop in levels of the Biological Oxygen Demand and the Total Hydrocarbon Contents of the contaminated water. The approach used here gave very encouraging results as earlier discussed.

- Stimulated Aspergillus Niger helped in the degradation of the hydrocarbon polluted water, using $0.2 \mathrm{M}$ sodium nitrate $\left(\mathrm{NaNO}_{3}\right)$ and $0.2 \mathrm{M}$ superphosphate fertilizer $\left(\mathrm{Ca}\left(\mathrm{H}_{2} \mathrm{PO}_{4}\right)_{2} \cdot \mathrm{H}_{2} \mathrm{O}\right)$ respectively.

- $0.2 \mathrm{M} \mathrm{NaNO} \mathrm{Na}_{3}$ (aq) is more efficient in stimulating the Aspergillus Niger as seen 
from the drop of $71.60 \%$ and $78.62 \%$ in BOD and $\mathrm{THC}$ respectively compared with that of $63.37 \%$ and $72.5 \%$ drop in BOD and $\mathrm{THC}$ for $0.2 \mathrm{M} \mathrm{Ca}\left(\mathrm{H}_{2} \mathrm{PO}_{4}\right)_{2} \cdot \mathrm{H}_{2} \mathrm{O}$ (aq) amended sample.

- The use of nutrients to stimulate the growth of microorganisms for bioremediation purposes on an industrial scale is a possibility and should be given the required attention.

\section{NOMECLATURE}

- THC- Total Hydrocarbon Content

- BOD- Biological Oxygen Demand

- M- Concentration (moles $/ \mathrm{dm}^{3}$ )

\section{REFERENCES}

Atlas, R.M. (1981). Microbial degradation of petroleum hydrocarbon. An environmental perspective. Microbiol. Rev. 45:180-20

Abril, G. (2000) Oxygen Measurement by Winkler titration.

Alexander, M. (1994). Biodegradation and Bioremediation. Academic Press, Inc. USA. pp 24-30.

Atlas, R.M., Horowitz, A., and Krichevsky, W. (1991). “ Response of Microbial population to environmental disturbance" Ecol 22, 249-256
Atlas R.M. and Bartha, R. (1992). Hydrocarbon biodegradation and oil spill bioremediation. In Advances in Microbial Ecology, Marshall, K.C. (ed) Vol. 12, Plenum, New York, USA. pp 287-338.

Atlas, R. M. (1995). Petroleum Biodegradation and Oil Spill Bioremediation. Marine Pollution Bulletin 31, 178-182.

Irvin, A.M. and Qianxin L. (1998) The Development for Oil Spill Cleanup in Coastal Wetlands: Product impacts and Bioremediation Potential.

Leaby J.G. and Colwell R.R. (1990): Microbial degradation of hydrocarbons in the environment. Microbiol Rev. 54: $305-315$

Marcus, F.W. and Christian P.K. (2007). The Journal of Biological Chemistry. 2729-2735.

Paula, A. (2007) Cities For Climate Protection, CCP Australia | Projects | Biodiesel Research Project, Biodiesel in Australia.

Richard, P.J. Swanel, K.L. and McDonagh, M. (1996) Field Evaluations of Marine Oil Spill Bioremediation, American Society for Microbiology.

Walker, J.D., Colwell, R.R. and Schwartz, J.R. (1974). Deep sea bacterial growth and utilization of hydrocarbons at ambient and in situ pressure. App. Bact. 25:987-990. 